\title{
Fas/CD95 Ligation Induces Proliferation of Primary Fetal Astrocytes Through a Mechanism Involving Caspase 8-Mediated ERK Activation
}

\author{
Olga Barca ${ }^{a}$ Marcos Seoane Rosa Ma Señarís Víctor M. Arce
}

Departamento de Fisioloxía, Facultade de Medicina. Universidade de Santiago de Compostela, 15782 Santiago de Compostela, Spain; aPresent address: Neuroscience and Brain Technologies Department, Italian Institute of Technology, Genoa, Italy

Key Words

Astrocytes • Fas/CD95 • ERK • PI-3K・Caspase 8

\begin{abstract}
Background: Fas/CD95 is the best-studied member of the death receptor (DR) superfamily in the central nervous system where it can trigger cellular responses other than apoptosis, including the promotion of neurogenesis and neuritogenesis, stimulation of the progression of gliomas, and regulation of the immune response of astrocytes. Methods: We have investigated the role of Fas/CD95 in the regulation of the proliferation of fetal astrocytes in vitro, as well as the signalling pathways involved. Results: Fas/CD95 ligation stimulated the proliferation of primary fetal astrocytes, through a mechanism that depends on the activation of caspase 8 and subsequent phosphorylation of extracellular signal regulated kinase (ERK). Interestingly this proliferative effect is only observed with a low dose of the Fas/CD95 agonist. In contrast, when primary astrocytes are challenged with a high dose of the Fas/CD95 agonist significant cell death occurs. Conclusions: Our findings support that, besides its effects on cell survival, Fas/CD95 may play a complex and prominent role in the regulation of astrocyte proliferation during development.
\end{abstract}




\section{Introduction}

The surface-bound receptor Fas (CD95) is a member of the death receptor (DR) superfamily that was initially identified in the immune system as an apoptosis-inducing receptor $[1,2]$. Once activated, Fas/CD95 triggers apoptosis through recruitment of the intracellular adaptor Fas-associated death domain (FADD, also called MORT1). FADD in turn recruits caspase 8 through interaction with their death effector domains (DED), leading to the assembly of a specific death-inducing signalling complex (DISC) at the intracellular region of the Fas/CD95 receptor. The recruitment of caspase 8 to the DISC results in autoproteolytic activation of the enzyme, which subsequently cleaves caspase 3 . In some cells, caspase 8 is inadequate to activate procaspase 3 and Fas/CD95-induced apoptosis signaling requires amplification through proteolytic activation of the pro-apoptotic Bcl-2 family member Bid (Bcl-2 inhibitory BH3-domain protein) [3-5].

As occurs with other death domain (DD)-containing receptors, Fas/CD95 has now emerged as an important regulator of several non-apoptotic functions in a wide range of cell types [6,7]. Thus, Fas/CD95 has been shown to increase the proliferation of human $\mathrm{T}$ lymphocytes and human fibroblasts in vitro $[8,9]$, to accelerate liver regeneration in mice subjected to partial hepatectomy [10], or even to promote tumour growth [11-15]. Other non-apoptotic activities of Fas/CD95 ligation include generation of proinflammatory cytokines and chemokines in various cell types, including astrocytes [16, 17], induction of a hypertrophic response in cultured cardiomyocytes [18], stimulation of the maturation of dendritic cells [19], induction of neurogenesis [20,21], or promotion of neurite outgrowth $[21,22]$. Although, the physiological importance of non-apoptotic functions of Fas/CD95 remains controversial, they have led to the general assumption of Fas/CD95 as a death receptor.

Up to now, the molecular mechanisms leading to the activation of the non-apoptotic actions of Fas/CD95 have not been completely elucidated. However, it is widely accepted that the essential components of the apoptotic signaling machinery may also exert a prominent role in the regulation of the non-apoptotic functions of Fas/CD95 [6, 23]. In this regard, caspase 8 has been reported to play an essential role in the hepatic regeneration following partial hepatectomy in mice [24] or in the stimulation of the maturation of cultured monocytes [25]. Similarly, blockade of the function of FADD results in defective liver regeneration [26] and impaired proliferation of $B$ and $T$ lymphocytes [27, 28].

Fas/CD95 is the best-studied DR in the central nervous system (CNS), and provides a good example of how divergent the DR-mediated biological effects may be. Within the CNS Fas/CD95 expression has been reported in both neurons and glial cells, including astrocytes and oligodendrocytes [revised in 16]. However, while both neurons and oligodendrocytes are susceptible to Fas/CD95-mediated apoptosis, astrocytes are quite resistant to Fas/CD95 death [17, 29-34]. In addition, Fas/CD95 can trigger cellular responses other than apoptosis in CNS cells, including the promotion of neurogenesis and neuritogenesis $[21,22,35,36]$, the stimulation of the progression of gliomas [12-14] and the regulation of the immune response of astrocytes [37-39].

In an attempt to gain further insight in the biological functions of Fas/CD95 signalling in astrocytes, we investigated its role in the regulation of the proliferation of fetal astrocytes in vitro. Our findings demonstrate that Fas/CD95 ligation induces a proliferative response in primary fetal astrocytes, via activation of caspase 8 and subsequent phosphorylation of extracellular signal regulated kinase (ERK). Interestingly, and in keeping with previous reports in both B and T cells $[7,40]$, this proliferative response seems to be dose-dependent: while low doses of the Fas/CD95 agonist stimulate cell proliferation, higher doses promote cell death. Altogether, our findings support a prominent role for Fas/CD95 in the regulation of the cellular fate of astrocytes during development. 


\section{Materials and Methods}

Cell cultures and treatments

Primary monolayer cultures of cortical astrocytes were established from fetal (embryonic day 15, E15) or neonatal (postnatal day 4.5, P4.5) Sprague-Dawley rat cerebral cortices as previously described $[41,42]$. The care and use of all experimental animals were in accordance with institutional guidelines. Cells were plated in Falcon polystyrene culture dishes (BD Biosciences, San Jose, CA) and grown in Dulbecco's modified Eagle's medium (Sigma-Aldrich, St. Louis, MO) supplemented with 5\% fetal bovine serum (FBS) (Invitrogen Corporation, Carlsbad, CA), $2 \mathrm{mM}$ glutamine, $2.5 \mathrm{U} / \mathrm{mL}$ penicillin, and $2.5 \mu \mathrm{g} / \mathrm{mL}$ streptomycin (all from Sigma-Aldrich). The cultures were maintained at $37^{\circ} \mathrm{C}$ in a humidified atmosphere of $5 \% \mathrm{CO}_{2}$ for one week and thereafter cells were trypsinized and subcultured for the different experiments. Astrocytes were characterized in culture by immunofluorescence using a monoclonal antibody against glial fibrillary acidic protein (GFAP) (Dako Diagnosticos, Barcelona, Spain) [43]. Hamster anti-Fas/CD95 antibody (Jo2) and its isotype control $\left(\operatorname{IgG}_{2} \lambda_{2}\right)$ were purchased from BD Biosciences. The specific caspase 8 inhibitor Z-IETD-fmk was purchased from Calbiochem (San Diego, CA). The ERK inhibitor PD98059 and the selective phosphatidylinositol 3-kinase (PI-3K) inhibitor LY294002 were purchased from Sigma-Aldrich.

\section{Cell proliferation assays}

In order to evaluate the effect of Fas/CD95 ligation on astrocyte proliferation, $4 \times 10^{4}$ cells were seeded in Falcon 24-well plates, and treated with with different concentrations of the agonistic antibody (5 or $10 \mu \mathrm{g} /$ $\mathrm{mL}$ ) or with the isotype antibody $\left(\operatorname{IgG}_{2} \lambda_{2}\right)$ for $24 \mathrm{~h}$. Cell number was determined with a Neubauer counting chamber. To assess the level of cell proliferation, astrocytes were labelled with bromodeoxyuridine (BrdU) using the FITC-BrdU Flow Kit (BD Biosciences) as described in the manufacturer's protocol. Briefly, BrdU was used at a final concentration of $10 \mu \mathrm{M}$, for the last $6 \mathrm{~h}$. After washing with the BD perm/wash buffer, cells were fixed and permeabilized with the BD cytofix/cytoperm buffer. Astrocytes were then treated with DNase for $1 \mathrm{~h}$ at $37^{\circ} \mathrm{C}$ and incubated with a fluoresceinated anti-BrdU antibody and with $4 \mu \mathrm{g} / \mathrm{mL}$ of Hoechst 33258, for $20 \mathrm{~min}$ at room temperature. Cells were examined under an Olympus fluorescence microscope (IX70, Olympus Optical Co, Tokyo, Japan) with the appropriate filter combination and photographed at a 40x magnification with a DP10 microscope digital camera (Olympus Optical Co). Four random fields were photographed for each replicate.

\section{Assessment of apoptosis}

Apoptotic cell death was assessed by fluorescence microscopic analysis of cell DNA staining patterns with Hoechst 33258, as previously described [41]. Cells were incubated with $4 \mu \mathrm{g} / \mathrm{mL}$ of Hoechst 33258 (Sigma-Aldrich) for $40 \mathrm{~min}$ at $37^{\circ} \mathrm{C}$ and, after washing, cell morphology was examined under an Olympus fluorescence microscope (IX70, Olympus Optical Co.) with the appropriate filter combination. Four random fields were photographed for each replicate, and cells were scored for apoptosis by their nuclear morphology (shrinkage, condensation, and fragmentation) and the higher intensity of blue fluorescence.

\section{Western blotting}

For phospho-ERK and phospho-Akt determination, cells were maintained in 1\% FBS for $48 \mathrm{~h}$ followed by serum starvation for $2 \mathrm{~h}$. Cells were collected by centrifugation, and the pellet was then lysated by heating at $95^{\circ} \mathrm{C}$ for $5 \mathrm{~min}$ in $1 \% \mathrm{SDS}$, and immediately cooled at $4^{\circ} \mathrm{C}$ for $15 \mathrm{~min}$ with ice-cold lysis buffer $(50 \mathrm{mM} \mathrm{Hepes}$, pH 7.5; 150 mM NaCl; 10\% Glycerol; 1\% Triton X-100; 5mM EGTA; 1.5 mM MgCl2; 20 mM Na4P2O7; 20 mM $\mathrm{Na} 3 \mathrm{VO} 4 ; 50 \mu \mathrm{g} / \mathrm{mL}$ aprotinin and $4 \mathrm{mM}$ phenylmethylsulfonyl fluoride). After centrifugation (15000 g, 15 $\min , 4^{\circ} \mathrm{C}$ ) to separate cellular debris, the lysates were resolved in a $12 \%$ SDS-PAGE, and electrotransferred onto a nitrocellulose paper (Protran; Schleicher and Schuell, Dassel, Germany). ERK phosphorylation was determined with a specific antibody that recognizes phospho-p44/42 (Erk1/2) (Cell Signalling Technology Inc, Danver, MA). Total ERK was determined for loading control (Cell Signalling Technology). For phosphoAkt determination, membranes were probed with a commercial kit (Phosphoplus Akt Ser473 Antibody Kit, New England Biolabs, USA) that allows specific recognition of both non-phosphorylated and serinphosphorylated Akt. Immunoreactive bands were detected with a western-light chemiluminiscence detection system (ECL, GE Healthcare Bio-Sciences AB, Uppsala, Sweden), photographed (HyperfilmECL, GE Healthcare Bio-Sciences) and scanned with a GelDoc system (Bio-Rad, Hercules, CA). 

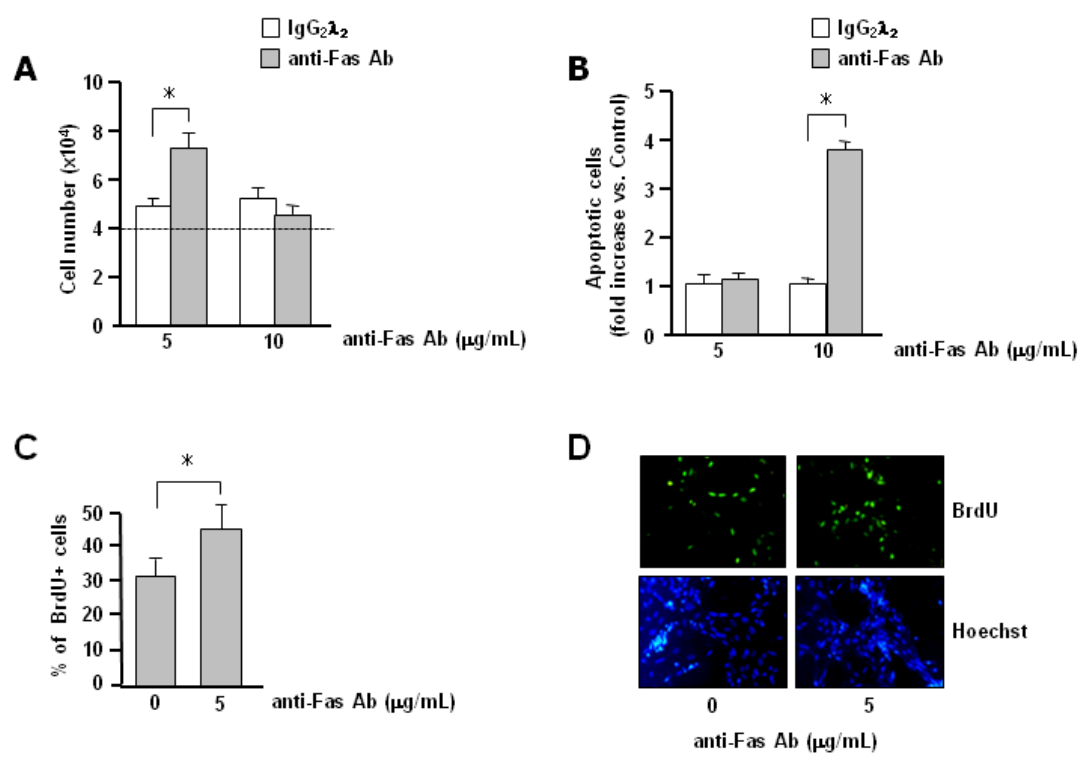

Fig. 1. Fas/CD95 ligation promotes proliferation in primary fetal astrocytes. A. Fas/CD95 engagement with the lower dose of the agonistic antibody $(5 \mu \mathrm{g} / \mathrm{mL})$ results in a significant increase in the cell number as compared with control cells. The dashed line indicates the cell counts at time 0 . Each bar represents the mean \pm S.E.M. of three independent experiments in triplicate. ${ }^{*}=p<0.05$ vs. control. $B$. A significant increase in the number of apoptotic cells is observed when astrocytes are treated with the higher dose of the agonist $(10 \mu \mathrm{g} / \mathrm{mL})$. Each bar represents the mean \pm S.E.M. of three independent experiments in triplicate. ${ }^{*}=p<0.05$ vs. control. $C$. Treatment of primary astrocytes with $5 \mu \mathrm{g} / \mathrm{mL}$ of anti-Fas/CD95 antibodies increases BrdU uptake. Each bar represents the mean \pm S.E.M. of three independent experiments in triplicate. ${ }^{*}=p<0.05 v S$. control. $D$. Representative images of the results shown in panel C.

\section{Statistical analysis}

Results are presented as the mean \pm standard error (SE). The effect of the different treatments was compared with their respective controls by using the non-parametric Mann-Whitney test. Statistical significance was established at $p<0.05$.

\section{Results}

Fas/CD95 ligation promotes proliferation in primary fetal astrocytes

Fas/CD95 engagement with the lower dose of the agonistic antibody $(5 \mu \mathrm{g} / \mathrm{mL}$ ) resulted in a significant increase in the cell number as compared with control cells (Fig. 1A). In contrast, cell number was not modified when primary astrocytes were challenged with a higher dose $(10 \mu \mathrm{g} / \mathrm{mL})$ of the anti-Fas/CD95 antibody (Fig. 1A). Cell number was also unaffected by challenging primary astrocytes with the isotype antibody. The lack of effect of the higher dose of the Fas/CD95 agonist on cell number may depend, at least in part, on the apoptotic response of primary astrocytes (Fig. 1B). A significant increase in the number of apoptotic cells was observed when astrocytes were treated with the higher dose of the agonist. In contrast, apoptotic cell death was not observed when primary astrocytes were challenged with the lower dose of the Fas/CD95 agonist (Fig. 1B). To gain further insight into the mechanisms that may account for the observed increase in cell number, primary astrocytes were treated with $5 \mu \mathrm{g} / \mathrm{mL}$ of anti-Fas/CD95 antibodies in the presence of BrdU. As expected, the raise in astrocyte number appears to be secondary to a stimulation of cell proliferation as demonstrated by the increased BrdU uptake (Fig. 1B and 1C). 


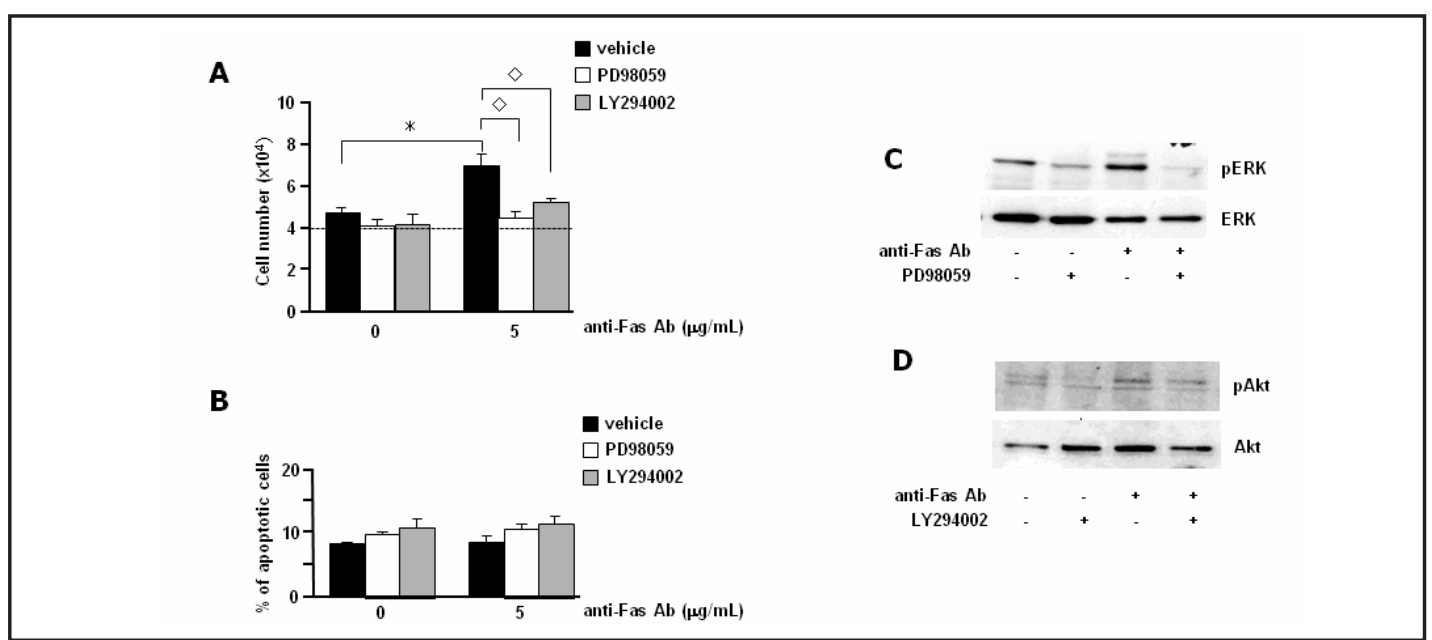

Fig. 2. ERK activation is necessary for Fas/CD95-induced astrocyte proliferation in primary fetal astrocytes. A. Blockade of either ERK or Akt phosphorylation with specific inhibitors results in a significant reduction in Fas/CD95-induced proliferation. The dashed line indicates the cell counts at time 0. Each bar represents the mean \pm S.E.M. of three independent experiments in triplicate. ${ }^{*}=p<0.05$ vs. control; $\diamond=p<0.05 v s$. antiFas/CD95. B. Blockade of either ERK or Akt phosphorylation with specific inhibitors does not affect cell survival. Each bar represents the mean \pm S.E.M. of three independent experiments in triplicate. C. Fas/CD95 engagement stimulates the phosphorylation of ERK in primary fetal astrocites, an effect that is completely abolished by PD98059. D. Akt phosphorylation is unchanged after Fas/CD95 treatment in primary fetal astrocites.

Fig. 3. ERK phosphorylation depends on caspase 8 activation in primary fetal astrocytes. A. Cell proliferation induced by Fas/CD95 ligation is completely abrogated when cells are treated in the presence of an irreversible inhibitor of caspase 8 . The dashed line indicates the cell counts at time 0 . Each bar represents the mean \pm S.E.M. of three independent experiments in triplicate. ${ }^{*}=p<0.05$ vs. control; $\diamond=p<0.05$ vs. anti-Fas/CD95. $B$ and $C$. Inhibition of caspase 8 decreases the amount of phosphorylated ERK detected after Fas/CD95 activation without affecting phospho-Akt levels.

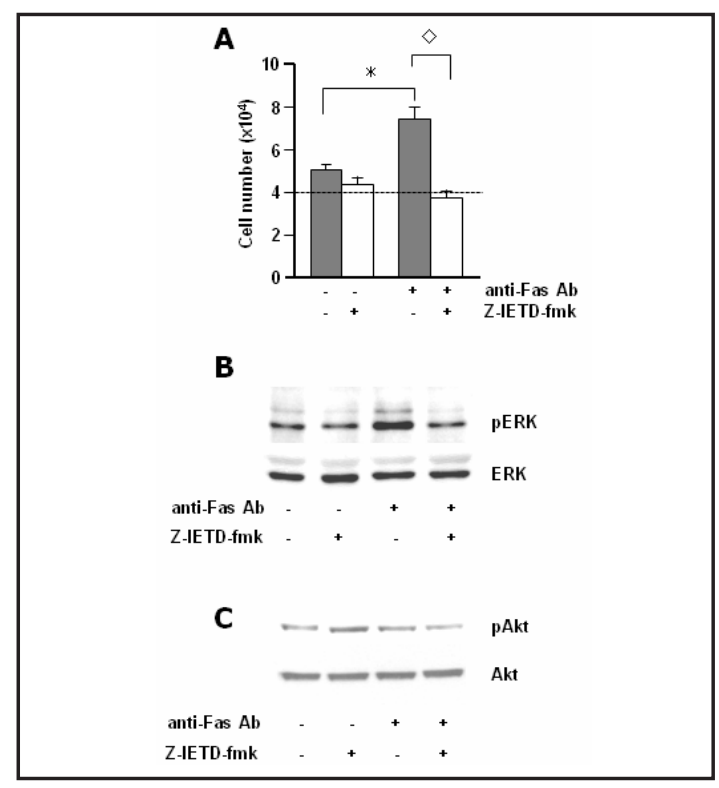

ERK activation is necessary for Fas/CD95-induced proliferation in primary fetal astrocytes

To gain further insight in the molecular mechanisms responsible for the Fas/CD95induced astrocyte proliferation, we investigated the involvement of the ERK and PI-3K/Akt pathways. Blockade of ERK phosphorylation with the specific MEK-1 inhibitor PD98059 resulted in a significant reduction in Fas/CD95-induced proliferation, without affecting cell survival (Fig. 2A and 2B). Furthermore, Fas/CD95 engagement clearly stimulated the phosphorylation of ERK in primary astrocytes, an effect that was completely abolished by PD98059 (Fig. 2C). Similarly, blockade of the PI-3K pathway also resulted in a decrease in Fas/CD95-induced proliferation, without affecting cell survival (Fig. 2A and 2B). However, 
A

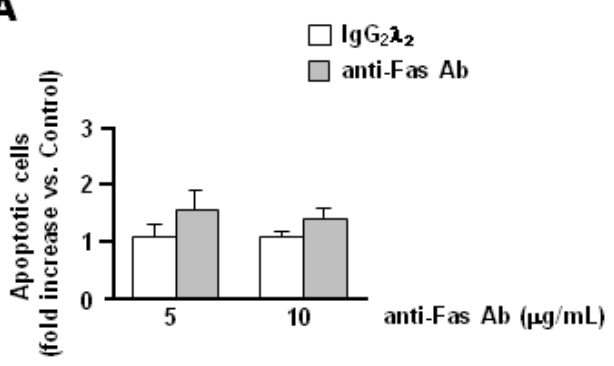

B

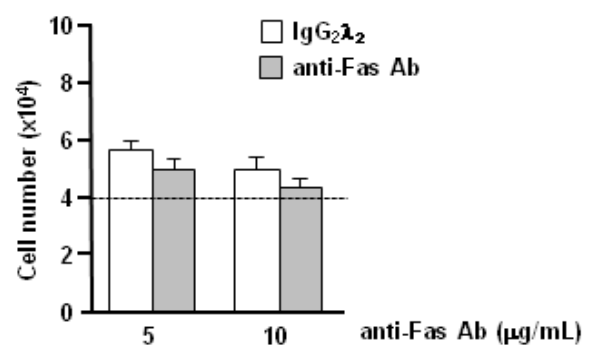

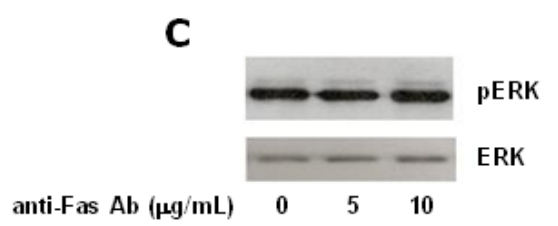

Fig. 4. Fas/CD95 ligation fails to promote cell proliferation in primary neonatal astrocytes. $A$. Neonatal astrocytes are resistant to Fas/CD95-driven apoptosis. Each bar represents the mean \pm S.E.M. of three independent experiments in triplicate. $B$. Treatment of neonatal astrocytes with activating anti-Fas/CD95 antibodies is unable to promote cell proliferation. The dashed line indicates the cell counts at time 0 . Each bar represents the mean \pm S.E.M. of three independent experiments in triplicate. $C$. Fas/CD95 ligation is unable to induce ERK phosphorylation in neonatal astrocytes.

and in contrast with the effect of Fas/CD95 engagement on ERK phosphorylation, we were unable to find any consistent effect of Fas/CD95 ligation on Akt phosphorylation (Fig. 2D).

ERK phosphorylation depends on caspase 8 activation in primary fetal astrocytes

In order to investigate the involvement of caspase-8 activation in Fas/CD95-induced proliferation, we treated the cells in the presence of an irreversible inhibitor of caspase 8. As Fig. 3A shows, the cell proliferation induced by Fas/CD95 ligation was completely abrogated under these experimental conditions, thus confirming that activation of caspase 8 is involved in Fas/CD95-induced proliferation. Interestingly, inhibition of caspase 8 also resulted in a decrease in the amount of phosphorylated ERK detected after Fas/CD95 activation (Fig. 3B), thus suggesting that ERK phosphorylation also depends on caspase 8 activity. In contrast, phospho-Akt levels were not modified by z-IETD-FMK treatment (Fig. 3C).

Fas/CD95 ligation fails to promote cell proliferation in primary neonatal astrocytes

The involvement of caspase 8 in Fas/CD95-induced proliferation was further investigated by treating rat neonatal astrocytes with Fas/CD95 agonist. As previously reported by our group [34], caspase 8 gene is inactivated in neonatal astrocytes and, therefore, we took advantage of this condition to confirm the involvement of caspase 8 in Fas/CD95-induced proliferation. In keeping with our hypothesis, treatment of neonatal astrocytes with activating anti-Fas/CD95 antibodies was unable to promote cell proliferation. Only a slight decrease in cell number was observed, though it did not reach statistical significance (Fig. 4B). Also in keeping with the results obtained when caspase 8 activity was inhibited in fetal astrocytes, Fas/CD95 ligation was unable to induce ERK phosphorylation in neonatal astrocytes (Fig. 4C). 


\section{Discussion}

\section{Fas/CD95 ligation promotes proliferation in primary fetal astrocytes}

Despite the expression of Fas/CD95 in astrocytes is well documented, its physiological role still remains to be elucidated. As a member of the DR family, Fas/CD95 has been reported to promote apoptosis in primary astrocytes [17, 34]. However, primary astrocytes are generally resistant to Fas/CD95 killing, at least under basal conditions [34, 37, 44, 45]; and resistance to Fas/CD95 killing has been even reported in glioma cells [14, 44]. Although the reasons for this resistance are not completely understood, we have recently proposed that silencing of caspase- 8 gene may be a key factor controlling the outcome of astrocytes upon Fas/CD95 engagement [34]. However, other mechanisms such as the expression levels of Fas/CD95, the presence of the Fas-associated protein phosphatase-1 (FAP-1), or the activation of cellular caspase 8 (FLICE)-like inhibitory protein (c-FLIP), may also confer astrocyte resistance to Fas/CD95-mediated cell death [45].

As occurs in other cell types, Fas/CD95 can also transduce non-apoptotic signals in primary astrocytes $[37,39,46]$. In keeping with this, our findings demonstrate that Fas/ CD95 ligation can induce a proliferative response in primary fetal astrocytes, but not in primary neonatal astrocytes, thus supporting a possible role for Fas/CD95 in the regulation of astrocyte proliferation during development. Remarkably, this proliferative response appears to be concentration-dependent, since it could be only observed when fetal astrocytes were challenged with the lower dose of the agonist. In contrast, stimulation with high concentrations of anti-Fas/CD95 antibodies resulted in a different scenario in which primary astrocytes underwent apoptosis. Interestingly, a similar dual effect has been also reported in both T and B lymphocytes [7, 40]. In those cells, low doses of Fas/CD95 agonists dramatically increase cell proliferation and activation, while high doses of the agonist may induce cell death $[7,40]$. Furthermore, a bimodal effect on astrocyte proliferation/death has been also recently reported for interferon $\beta$ [47] thus further illustrating the complexity of the mechanisms involved in the regulation of astrocyte fate during development.

\section{Caspase 8 activation is necessary for Fas/CD95-induced astrocyte proliferation}

To the present, little is known about the molecular mechanisms involved in the control of Fas/CD95-induced proliferation. However, it is now widely accepted that the essential components of the pro-death activity are also critically involved in its non-apoptotic consequences. This is the case of caspase 8 , the primary caspase that is recruited to the DISC and, consequently, the most apical component of the Fas/CD95 death signaling pathway [3, 7]. It has been reported that recruitment and activation of caspase 8 may be also necessary for the non-apoptotic functions of Fas/CD95 and, in this regard, caspase 8 is required for cytokine-induced proliferation of hemopoietic progenitor cells and T cells, and it is also necessary for cytokine-induced monocyte differentiation [25, 48, 49]. In addition, capase 8 positively controls proliferation and cell-cycle progression in primary hepatocytes [50]. The results presented here demonstrate the importance of caspase 8 in the control of the proliferation of fetal astrocyts since (i) Fas/CD95-induced proliferation of fetal astrocytes is counteracted by inhibition of caspase 8 activity, and (ii) Fas/CD95-induced proliferation is absent in neonatal astrocytes, in which, allegedly caspase 8 gene is inactivated [34].

It is presently unclear whether these proliferative effects of caspase 8 require the preservation of its enzymatic activity. However, it is important to indicate that enzymatic inhibition of caspase 8 impairs the Fas/CD95-induced proliferation in T cells [48], myeloid progenitors [49] or primary fetal astrocytes (the present study). However, we cannot rule out that some other functions of caspase 8, or even caspase 8 independent mechanisms [40] may be also involved in the proliferative effects of Fas/CD95.

Caspase 8-mediated ERKactivation is involved in Fas/CD95-induced astrocyte proliferation

To further establish the functional relevance of Fas/CD95-driven proliferation, we analyzed some of the signaling pathways that may be involved in this response. The 
importance of ERK phosphorylation in transducing the non-apoptotic functions of Fas/ CD95 has been previously demonstrated in different cell types [13, 21, 22, 40]. Remarkably, the consequences of Fas/CD95-induced ERK activation include the promotion of tumor progression of Fas/CD95 apoptosis-resistant tumor cells [12-14] or in primary fetal astrocytes (the present study). Although the molecular link between Fas/CD95 engagement and ERK phosphorylation has not been uncovered yet, based in our findings, it appears that the process requires the enzymatic activity of caspase 8. In contrast with our findings, it has been reported that ERK activation is not blocked in a B lymphoblastoid cell line by the addition of the pan-caspase inhibitor Z-VAD-fmk [40]. Although we do not presently know the reasons for these discrepancies, we cannot rule out the existence of differences in the caspase 8 activation within the DISC, or the participation of yet uncharacterized proteins.

The PI-3K/Akt pathway is another prominent signalling mechanism involved in some of the non-apoptotic functions of Fas/CD95 [see 43 for review]; and PI-3K has been recently reported as an important mediator of Fas/CD95 effects on glioma cells [36]. Reportedly, Fas/CD95 stimulation induces a strong phosphorylation of the catalytic unit of PI-3K in both Jurkat and apoptosis-sensitive glioma cells [11]. However, despite we have found that blockade of PI-3K signaling reduces Fas/CD95-induced proliferation, we have been unable to demonstrate any effect of Fas/CD95 engagement on the activation of the PI-3K/Akt pathway. Interestingly, other studies have also failed in detecting increased activity of PI-3K in CD95 apoptosis-resistant glioma cells [11, 14]. Furthermore, since activation of PI-3K by Fas/ CD95 does not requires caspase activity [14], it is tempting to speculate that the PI-3K/Akt pathway is not a key component of the signaling mechanisms involved in the non-apoptotic effects of Fas/CD95 activation.

In summary, we have found that Fas/CD95 engagement may induce a dual effect in fetal astrocytes: high doses of a Fas/CD95 agonist may induce cellular apoptosis, while low doses promote astrocyte proliferation. The growth promoting function of Fas/CD95 appears to be secondary to caspase 8-mediated activation of the ERK signaling pathway. Altogether, our findings suggest the FasL-Fas/CD95 system may play an important role in the regulation of astrocyte biology during development. In contrast, the importance of the FasL-Fas/CD95 system in postnatal astrocytes may be limited by the fact that these cells do not express caspase-8.

\section{Disclosure}

This work was supported in part by grants from Xunta de Galicia (Axudas para a consolidación das unidades de investigación do Sistema Galego de Investigación e Innovación).

\section{References}

1 Itoh N, Yonehara S, Ishii A, Yonehara M, Mizushima S, Sameshima M, Hase A, Seto Y, Nagata S: The polypeptide encoded by the cDNA for human cell surface antigen Fas can mediate apoptosis. Cell 1991;66:233-243.

- Oehm A, Behrmann I, Falk W, Pawlita M, Maier G, Klas C, Li-Weber M, Richards S, Dhein J, Trauth BC, Ponstingl H, Krammer PH: Purification and molecular cloning of the APO-1 cell surface antigen, a member of the tumor necrosis factor/nerve growth factor receptor superfamily. Sequence identity with the antigen. J Biol Chem 1992;267:10709-10715.

3 Wajant H: The Fas signaling pathway: more than a paradigm. Science 2002;296:1635-1636.

4 Curtin JF, Cotter TG: Live and let die: regulatory mechanisms in Fas-mediated apoptosis. Cell Signal 2003;15:983-992.

5 Kavurma MM, Khachigian LM: Signaling and transcriptional control of Fas ligand gene expression. Cell Death Differ 2003;10:36-44.

6 Strasser A, Jost PJ, Nagata S: The many roles of FAS receptor signaling in the immune system. Immunity 2009;30:180-192. 
Barca/Seoane/Señarís/Arce: Fas-Induced Astrocyte Proliferation

7 Paulsen M, Janssen O: Pro- and anti-apoptotic CD95 signaling in T cells. Cell Commun Signal 2011;9:7.

-8 Alderson M, Armitage RJ, Maraskovsky E, Tough TW, Roux E, Schooley K, Ramsdell F, Lynch DH: Fas transduces activation signals in normal human T lymphocytes. J Exp Medcine 1993;178:2231-2235.

-9 Aggarwal BB, Singh S, LaPushin R, Totpal K: Fas antigen signals proliferation of normal human diploid fibroblast and its mechanism is different from tumor necrosis factor receptor. FEBS Let 1995;364:5-8.

10 Desbarats J, Newell MK: Fas engagement accelerates liver regeneration after partial hepatectomy. Nat Med 2000; 6:920-923.

11 Gulbins E, Hermisson M, Brenner B, Grassme HU, Linderkamp O, Dichgans J, Weller M, Lang F: Cellular stimulation via CD95 involves activation of phospho-inositide-3-kinase. Pflugers Arch 1998;435:546-554.

12 Shinohara H, Yagita H, Ikawa Y, Oyaizu N: Fas drives cell cycle progression in glioma cells via extracellular signal-regulated kinase activation. Cancer Res 2000;60:1766-1772.

13 Barnhart BC, Legembre P, Pietras E, Bubici C, Franzoso G, Peter ME: CD95 ligand induces motility and invasiveness of apoptosis-resistant tumor cells. EMBO J 2004;23:3175-3185.

14 Zuliani C, Kleber S, Klussmann S, Wenger T, Kenzelmann M, Schreglmann N, Martinez A, del Rio JA, Soriano E, Vodrazka P, Kuner R, Groene HJ, Herr I, Krammer PH, Martin-Villalba A: Control of neuronal branching by the death receptor CD95 (Fas/Apo-1). Cell Death Differ 2006;13:31-40.

15 Chen L, Park SM, Tumanov AV, Hau A, Sawada K, Feig C, Turner JR, Fu YX, Romero IL, Lengyel E, Peter ME: CD95 promotes tumour growth. Nature 2010;465:492-496.

$\checkmark 16$ Choi C, Benveniste EN: Fas ligand/Fas system in the brain: regulator of immune and apoptotic responses. Brain Res Rev 2004;44:65-81.

17 Falsig J, Latta M, Leist M: Defined inflammatory states in astrocyte cultures:correlation with susceptibility towards CD95-driven apoptosis. J Neurochem 2004;304:181-193.

18 Badorff C, Ruetten H, Mueller S, Stahmer M, Gehring D, Jung F, Ihling C, Zeiher AM, Dimmeler S: Fas receptor signaling inhibits glycogen synthase kinase 3 beta and induces cardiac hypertrophy following pressure overload. J Clin Invest 2002;109:373-381.

19 Rescigno M, Piguet V, Valzasina B, Lens S, Zubler R, French L, Kindler V, Tschopp J, Ricciardi-Castagnoli P: Fas engagement induces the maturation of dendritic cells (DCs), the release of interleukin (IL)-1 $\beta$, and the production of interferon $\gamma$ in the absence of IL-12 during DC-T cell cognate interaction: a new role for Fas ligand in inflammatory responses. J Exp Med 2000;192:1661-1668.

20 Ricci-Vitiani L,Pedini F, Mollinari C, Condorelli G, Bonci D, Bez A, Colombo A, Parati E, Peschle C, De Maria R: Absence of caspase 8 and high expression of PED protect primitive neural cells from cell death. J Exp Med 2004;200:1257-1266.

-21 Tamm C, Robertson JD, Sleeper E, Enoksson M, Emgård M, Orrenius S, Ceccatelli S: Differential regulation of the mitochondrial and death receptor pathways in neural stem cells. Eur J Neurosci 2004;19:2613-2621.

22 Desbarats J, Birge RB, Mimouni-Rongy M, Weinstein DE, Palerme JS, Newell MK: Fas engagement induces neurite growth through ERK activation and p35 upregulation. Nat Cell Biol 2003;5:118-125.

23 Newton K, Strasser A: Caspases signal not only apoptosis but also antigen-induced activation in cells of the immune system. Gen Dev 2003;17:819-825.

24 Ben Moshe T, Barash H, Kang TB, Kim JC, Kovalenko A, Gross E, Schuchmann M, Abramovitch R, Galun E, Wallach D: Role of caspase-8 in hepatocyte response to infection and injury in mice. Hepatology 2007;45:1014-1024.

-25 Kang TB, Ben-Moshe T, Varfolomeev EE, Pewzner-Jung Y, Yogev N, Jurewicz A, Waisman A, Brenner O, Haffner R, Gustafsson E, Ramakrishnan P, Lapidot T, Wallach D: Caspase-8 serves both apoptotic and nonapoptotic roles. J Immunol 2004;173:976-2984.

-26 Schuchmann M, Ruckert F, Garcia-Lazaro JF, Karg A, Burg J, Knorr N, Siebler J, Varfolomeev EE, Wallach D, Schreiber W, Lohse AW, Galle PR: MORT1/FADD is involved in liver regeneration. World J Gastroenterol 2005;11:7248-7253.

27 Newton K, Harris AW, Bath ML, Smith KGC, Strasser A: A dominant interfering mutant of FADD/Mort1 enhances deletion of autoreactive thymocytes and inhibits proliferation of mature T lymphocytes. EMBO J 1998;17:706-718.

28 Imtiyaz HZ, Rosenberg S, Zhang Y, Rahman ZS, Hou YJ, Manser T, Zhang J: The Fas-associated death domain protein is required in apoptosis and TLR-induced proliferative responses in B cells. J Immunol 2006;176:6852-6861. 
Barca/Seoane/Señarís/Arce: Fas-Induced Astrocyte Proliferation

29 D'Souza SD, Bonetti B, Balasingam V, Cashman NR, Barker PA, Troutt AB, Raine CS, Antel JP: Multiple sclerosis: Fas signaling in oligodendrocyte cell death. J Exp Med 1996;184:2361-2370.

-30 Cheema ZF, Wade SB, Sata M, Walsh K, Sohrabji F, Miranda RC: Fas/Apo [apoptosis]-1 and associated proteins in the differentiating cerebral cortex: induction of caspase-dependent cell death and activation of NF-кB. J Neurosci 1999;19:1754-1770.

-31 Le-Niculescu H, Bonfoco E, Kasuya Y, Claret FX, Green DR, Karin M: Withdrawal of survival factors results in activation of the JNK pathway in neuronal cells leading to Fas ligand induction and cell death. Mol Cell Biol 1999;19:751-763.

-32 Choi C, Park JY, Lee J, Lim JH, Shin EC, Ahn YS, Kim CH, Kim SJ, Kim JD, Choi IS, Choi IH: Fas ligand and Fas are expressed constitutively in human astrocytes and the expression increases with IL-1, IL-6, TNF-alpha, or IFN-gamma. J Immunol 1999;162:1889-1895.

33 Pouly S, Becher B, Blain M, Antel JP: Interferon- $\gamma$ modulates human oligodendrocyte susceptibility to Fasmediated apoptosis. J Neuropathol Exp Neurol 2000;59:280-286.

-34 Barca O, Carneiro C, Costoya JA, Señarís RM, Arce VM: Resistance of neonatal primary astrocytes against Fas-induced apoptosis depends on silencing of caspase 8. Neurosci Lett 2010;479:206-210.

35 Ceccatelli S, Tamm C, Sleeper E, Orrenius S: Neural stem cells and cell death. Toxicol Lett 2004;149:59-66.

-36 Kleber S, Sancho-Martinez I, Wiestler B, Beisel A, Gieffers C, Hill O, Thiemann M, Mueller W, Sykora J, Kuhn A, Schreglmann N, Letellier E, Zuliani C, Klussmann S, Teodorczyk M, Gröne HJ, Ganten TM, Sültmann H, Tüttenberg J, von DeimLing A, Regnier-Vigouroux A, Herold-Mende C, Martin-Villalba A: Yes and PI3K bind CD95 to signal invasion of glioblastoma. Cancer Cell 2008;13:235-248.

-37 Lee SJ, Zhou T, Choi C, Wang Z, Benveniste EN: Differential regulation and function of Fas expression on glial cells. J Immunol 2000;164:1277-1285.

-38 Dietrich PY, Walker PR, Saas P: Death receptors on reactive astrocytes: a key role in the fine tuning of brain inflammation? Neurology 2003;60:548-554.

-39 Saas P, Boucraut J, Quiquerez AL, Schnuriger V, Perrin G, Desplat-Jego S, Bernard D, Walker PR, Dietrich PY: CD95 (Fas/Apo-1) as a receptor governing astrocyte apoptotic or inflammatory responses: a key role in brain inflammation? J Immunol 1999;162:2326-2333.

40 Lavrik IN, Golks A, Riess D, Bentele M, Eils R, Krammer PH: Analysis of CD95 threshold signaling: triggering of CD95 (FAS/APO-1) at low concentrations primarily results in survival signaling. J Biol Chem 2007;282:13664-13671.

41 Barca 0, Ferré S, Seoane M, Prieto JM, Lema M, Señarís R, Arce VM: Interferon beta promotes survival in primary astrocytes through phosphatidylinositol 3-kinase. J Neuroimmunol 2003;139:155-159.

-42 Barca 0, Costoya JA, Señarís RM, Arce VM: Interferon-beta protects astrocytes against tumour necrosis factor-induced apoptosis via activation of p38 mitogen-activated protein kinase. Exp Cell Res 2008;314:2231-2237.

43 Quintela M, Senaris RM, Dieguez C: Transforming growth factor-beta inhibit somatostatin messenger ribonucleic acid levels and somatostatin secretion in hypothalamic cells in culture. Endocrinology 1997;138:4401-4409.

-44 Wosik K, Becher B, Ezman A, Nalbantoglu J, Antel JP: Caspase 8 expression and signaling in Fas injuryresistant human fetal astrocytes. Glia 2001;33:217-224.

45 Becher B, D'Souza SD, Troutt AB, Antel JP: Fas expression on human fetal astrocytes without susceptibility to fas-mediated cytotoxicity. Neuroscience 1998;84:627-634.

46 Choi K, Li N, Jonakait GM: Fas ligation and tumor necrosis factor alpha activation of murine astrocytes promote heat shock factor-1 activation and heat shock protein expression leading to chemokine induction and cell survival. J. Neurochem 2011;116:438-448.

47 Barca 0, Devesa-Peleteiro P, Seoane M, Señarís RM, Arce VM: Bimodal effect of interferon- $\beta$ on astrocyte proliferation and survival: Importance of nuclear factor- $\kappa$ B. J Neuroimmunol 2010;226:73-80.

48 Kennedy NJ, Kataoka T, Tschopp J, Budd RC: Caspase activation is required for T cell proliferation. J Exp Med 1999;190:1891-1896.

49 Pellegrini M, Bath S, Marsden VS, Huang DC, Metcalf D, Harris AW, Strasser A: FADD and Caspase-8 are required for cytokine-induced proliferation of hemopoietic progenitor cells. Blood 2005;106:1581-1589.

-50 Gilot D, Serandour AL, Ilyin GP, Lagadic-Gossmann D, Loyer P, Corlu A, Coutant A, Baffet G, Peter ME, Fardel O, Guguen-Guillouzo C: A role for caspase-8 and c-FLIPL in proliferation and cell-cycle progression of primary hepatocytes. Carcinogenesis 2005;26:2086-2094. 